\title{
Epidemiological Study on Risk Factors for Anxiety Disorder among Chinese Doctors
}

\author{
Wei Sun ${ }^{1,2}$, Jialiang Fu${ }^{1}$, Ying $\mathrm{CHANG}^{1}$ and Lie WANG ${ }^{1}$ \\ ${ }^{1}$ Department of Social Medicine, School of Public Health, China Medical University and ${ }^{2}$ Department of \\ Environmental Health, School of Public Health, China Medical University, P.R. China
}

\begin{abstract}
Epidemiological Study on Risk Factors for Anxiety Disorder among Chinese Doctors: Wei Sun, et al. Department of Social Medicine, School of Public Health, China Medical University, P.R. China-Objectives: Anxiety disorders are the most prevalent mental health problem. However, few studies are available pertaining to this problem among Chinese doctors, a special occupational population exposed to high stress, especially during the implementation of health system reform. The aim of this study was to assess anxiety disorder among Chinese doctors and clarify its risk factors. Methods: A cross-sectional study was conducted in 7 teaching hospitals of China Medical University. Questionnaires pertaining to anxiety disorder indicated by the Zung Self-Rating Anxiety Scale (SAS) and demographic characteristics, health status, lifestyle factors, work conditions and work-related psychological status were distributed to all registered doctors during April-June 2009. There were 1,134 effective respondents (effective response rate $71.2 \%$ ), and these respondents became our subjects (539 male doctors and 595 female doctors). Results: The average standard scores of SAS for the male and female doctors were 46.8 and 46.7. General linear model analysis indicated that SAS was associated with, in standardized estimate $(\beta)$ sequence, cynicism, emotional exhaustion, professional efficacy, sleeping problem, chronic diseases and physical exercise in men and with professional efficacy, emotional exhaustion, cynicism, sleeping problem, chronic diseases, job satisfaction, alcohol consumption and meals in women. Work-related psychological status contributed the most to the model R-square. Conclusion: Chinese doctors were at considerably high risk of anxiety disorder and job burnout and sleeping problem had prominent roles. Interventions such as preventing exhaustion at work and improv-
\end{abstract}

Received Aug 10, 2011; Accepted Oct 12, 2011

Published online in J-STAGE Dec 10, 2011

Correspondence to: L. Wang, Department of Social Medicine, School of Public Health, China Medical University, 92 Bei'er Road, Heping District, Shenyang, 110001, P.R. China (e-mail: liewang@mail. cти.edu.cn) ing sleep quality should be given attention during health care system reform with the aim of lessening anxiety disorder in doctors in China.

(J Occup Health 2012; 54: 1-8)

Key words: Anxiety disorder, China, Doctors, Job burnout, Sleeping problem

Anxiety is a basic human emotion, an uncomfortable feeling related to uneasiness, apprehension or worry. At the beginning of 21 st century, anxiety disorders became the most prevalent mental health problem affecting the quality of life around the globe ${ }^{1,2)}$. Its lifetime prevalence ranged from 13.6 to $28.8 \%$ in the general population ${ }^{3,4)}$. Moreover, anxiety disorders have high comorbidity rates with other psychiatric disorders ${ }^{5}$. Thus, their impact has become comparable to that of chronic somatic disorders ${ }^{6}$.

Doctors, as a particular occupational population coping with the cure of illness and directly confronting suffering, disease and death everyday, tend to have a high risk of mental health disorders ${ }^{7,8)}$. Unfortunately, mental disorders in doctors can lead to medical mistakes and adversely affect their attitude towards patient care ${ }^{9,10)}$. Therefore, how to improve the mental health of doctors has become an accelerating social concern for the quality of lives of not only doctors themselves but also the whole general population. This issue seems to be particularly serious in China because of the heavy patient load resulting from the huge population. The ratio of doctors to the general population is $1: 735$ in China, considerably lower than that in western countries $(1: 280-1: 640)^{11)}$. As a result, medical disputes occur more frequently than before. Moreover, China is undertaking health care system reform in which the focus is transforming from disease to health and from sustaining life to quality of life. The traditional disease-centered care model had been gradually replaced by the patient-centered care model. This 
China-specific reform is expected to inevitably deteriorate the mental health problems of doctors. It has been reported that, at present, most Chinese doctors suffer from depressive symptom ${ }^{12}$. However, anxiety disorder, the most prevalent mental health problem affecting quality of life, has been few studied among Chinese doctors up to now.

The purpose of the present study was to assess anxiety disorder among Chinese doctors and explore its risk factors. Since most situations that trigger anxiety are work-related ${ }^{13)}$, work conditions (administrative leadership, professional rank, work arrangement, night shift, prepost training and on-the-job training) and work-related psychological status (bored with patient, effort-reward imbalance, job satisfaction and job burnout) were considered to clarify the factors associated with anxiety disorder among Chinese doctors. In view of the fact that health status is the basis of any disorder and illness, chronic diseases and sleeping problems that had been reported to be a common disturbance in the work population ${ }^{14)}$ were taken into account. Also, lifestyle factors such as nutrition, food intake and alcohol consumption have been revealed to be the main determinants of anxiety disorder ${ }^{15)}$. Thus, work conditions and work-related psychological status, health status and lifestyle factors along with demographic characteristics were investigated in the present study to clarify the factors in relation to anxiety disorder among Chinese doctors.

\section{Materials and Methods}

\section{Study population}

China Medical University was the first medical school established by the Chinese Communist Party and has been the prominent medical institution in northeast China. It has 7 teaching hospitals dispersed throughout Liaoning Province which has almost same income level as the average level and a proportion of health workers who are doctors $(34.5 \%)$ comparable to that of the whole nation $(35.4 \%)$ according to the China Yearbook. These teaching hospitals, 6 "grade one" hospitals (>500 beds) and 1 "grade two" hospital (101-500 beds), became our approaches to accessing to doctors. All registered doctors in these teaching hospitals composed our study population, a total of 1,593 registered doctors. After obtaining written consent to conduct this survey, questionnaires were distributed to these participants during April-June 2009. We received effective responses from 1,134 doctors (effective response rate $71.2 \%$ ). These doctors became our study subjects.

\section{Assessment of anxiety disorder}

Anxiety covers a variety of anxiety disorders. Somatic complaints represent a core feature of anxiety pathology and have been implicated in some kinds of anxiety disorder ${ }^{16)}$. Thus, the Zung Self-Rating Anxiety Scale (SAS) that was designed by William WK Zung with focus on somatic complaints ${ }^{17)}$ was used as the indicator of anxiety disorder in the present study. It composed 20 questions with 4 possible responses: (1) never, (2) rarely/sometimes, (3) frequently and (4) always. Each item was scored from 1 to 4 according to severity. The raw score was standardized according to the formula: standard score $=$ int $(1.25 *$ raw score $) . \quad$ A higher score denoted more serious anxiety disorder.

Measurements of demographic characteristics, health status, lifestyle factors, work conditions and workrelated psychological status

Demographic characteristics included age, sex, marital status, education and monthly income. In China, health workers who graduated from junior college are able to obtain a doctor's license after they have become a licensed assistant doctor and experienced years of medical practice. Thus, education was categorized as junior college, undergraduate and graduate $^{18)}$. As for marital status, only 10 men (1.90\%) and 20 women $(3.47 \%)$ belonged to the widow/ divorced/separated group. Thus, they were combined with the single group as others. Monthly income (dollars) was divided into <292.8, 292.8-439.2 and $>439.2$ groups.

Health status was assessed on the basis of 2 items: 1) chronic diseases and 2) sleeping problem. Chronic diseases were defined as present if any disease such as hypertension, cardiovascular disease, diabetes, stoke or peptic ulcers had ever been diagnosed ${ }^{19}$. Sleeping problem was determined by asking the question "Do you have difficulty in sleeping (no/slight/serious)?".

Lifestyle factors included smoking, alcohol consumption, meals and physical exercise. Physical exercise was examined according to the frequency of doing exercise as none, once a week and twice or more a week ( $\geq 2$ times/wk).

Work conditions included 6 items: 1) administrative leadership, 2) professional rank, 3) work arrangement, 4) night shift, 5) prepost training and 6) on-thejob training. Administrative leadership was assessed with the question "Are you the administrative leader in your department (yes/no)?" Professional rank was categorized as primary, middle and senior. Work arrangement was categorized as fixed and shift groups. Night shift, prepost training and on-the-job training were determined by asking the questions "Do you work night shift (yes/no)?", "Had you ever attended prepost training before taking this job (yes/no)?" and "Have you ever participated in any professional training program while working (yes/no)?" respectively. 
Work-related psychological status referred to 4 items: 1) bored with patients, 2) effort-reward imbalance (ERI), 3) job satisfaction and 4) job burnout. Bored with patients was measured by asking the question "How often do you feel bored dealing with relationships with patients?" with 5 possible answers (never, rarely, sometimes, frequently and always). The answers were categorized into never, general and serious groups by combining the response rarely with the response sometimes and the response frequently with the response always. ERI was tested by the Chinese version of the ERI questionnaire ${ }^{20,21)}$ to claim the failed reciprocity in terms of high efforts spent and low rewards received in turn. It contained extrinsic effort (6 items), reward (11 items) and overcommitment (6 items). Each response for extrinsic effort and reward was scored from 1 to 5, and higher total scores indicated higher demands of efforts and higher rewards. The effort/reward ratio calculated according to the formula ratio=extrinsic effort / (reward*0.5454) indicated "stressful" if the ratio was over 1 . Responses for overcommitment were scored on a scale of 1 , representing complete disagreement, to 4, representing complete agreement. A higher score suggested higher demands characterized by excessive work-related commitment. Job satisfaction was assessed by the short form of the Minnesota Satisfaction Questionnaire (MSQ), which has been used widely in the Chinese population ${ }^{22}$. It comprised 20 items with 5 possible responses scored on a scale of 1, representing completely dissatisfied, to 5 , representing completely satisfied. The total score was used as the indicator of job satisfaction. Job burnout was measured with the Chinese version of the Maslach Burnout Inventory-General Survey (MBI-GS), which has been well applied in health workers $^{23,24)}$. It included three scales: emotional exhaustion (5 items), cynicism (4 items) and professional efficacy (6 items). Each item has 7 possible answers: (1) never, (2) rarely (several times per year), (3) sometimes (once a month), (4) often (several times per month), (5) frequently (once a week), (6) always (several times per week) and (7) everyday. These responses were scored from 0 to 6 . A higher score implicated serious exhaustion and cynicism and higher professional efficacy.

\section{Statistical analysis}

Among all categorical independent variables, items to which over $95 \%$ of individuals had the same responses were not included in the data analysis. Smoking in women $(2.1 \%)$ was thereby excluded.

Data analyses were performed separately for men and women. The standard score of SAS was used to conduct statistical analysis. Distributions of anxi- ety disorder in categorical items were tested by the Student's $t$-test and one-way ANOVA. Correlations of anxiety disorder with continuous variables were tested by Pearson correlation. The different characteristics between male and female doctors were examined by the Student's $t$-test and chi-square test for continuous variables and categorical variables respectively. General linear model analysis was used to clarify the risk factors for anxiety disorder. All variables that were significant at the 0.25 level in univariate analysis were entered in the model. With adjustment for age, items with $p>0.15$ were eliminated one at a time in the sequence of $p$ value. When an item was eliminated, if the change in any remaining parameter estimate was greater than $20 \%$, this item would be remained in the model as a confounder. In this study, no confounder was found during elimination. SAS for Windows, Ver. 8.2, was used for all statistical analyses.

\section{Results}

The characteristics of the participants and the correlations of anxiety disorder with continuous variables are shown in Table 1. The standard score of SAS was $46.8 \pm 11.09$ (mean \pm SD) in male doctors and $46.7 \pm 10.85$ in female doctors respectively. Male doctors had significantly higher scores of cynicism, extrinsic effort and reward than female doctors. In both male and female doctors, the standard score of SAS was significantly correlated with extrinsic effort, reward, overcommitment, job satisfaction and all scales of job burnout.

The subject characteristics and the distributions of anxiety disorder in categorical items are shown in Table 2. In comparison with female doctors, male doctors had significantly lower education but significantly higher levels of chronic diseases, alcohol consumption, irregular meals and physical exercise. In male doctors, the standard score of SAS had significant relations with education, chronic diseases, sleeping problem, meals, physical exercise, work arrangement and bored with patients; whereas, it was significantly related to chronic diseases, sleeping problem, alcohol consumption, meals, administrative leadership, bored with patients, and effort/reward ratio in female doctors.

The results of the general linear model analysis for clarifying the major risk factors for anxiety disorder are shown in Table 3. With adjustment for age, the standard score of SAS was significantly associated with, in the sequence of standardized estimate $(\beta)$, cynicism, emotional exhaustion, professional efficacy, sleeping problem, chronic diseases and physical exercise in male doctors and with professional efficacy, emotional exhaustion, cynicism, sleeping problem, chronic diseases, job satisfaction, alcohol consumption 
Table 1. The characteristics of the participants and the correlations of anxiety disorder with continuous variables

\begin{tabular}{lcccc}
\hline \multirow{2}{*}{ Variables } & \multicolumn{2}{c}{ Male $(\mathrm{n}=539)$} & \multicolumn{2}{c}{ Female $(\mathrm{n}=595)$} \\
\cline { 2 - 5 } & Mean $\pm \mathrm{SD}$ & $r$ & Mean $\pm \mathrm{SD}$ & $r$ \\
\hline Standard SAS score & $46.8 \pm 11.09$ & & $46.7 \pm 10.85$ & \\
Age (yr) & $38.5 \pm 9.25$ & -0.05 & $37.5 \pm 8.31$ & 0.05 \\
Overcommitment & $13.7 \pm 2.08$ & $0.21^{* *}$ & $13.6 \pm 2.00$ & $0.27^{* *}$ \\
Job satisfaction & $63.9 \pm 12.57$ & $-0.35^{* *}$ & $63.7 \pm 11.10$ & $-0.38^{* *}$ \\
Emotional exhaustion & $11.8 \pm 7.94$ & $0.46^{* *}$ & $11.7 \pm 7.18$ & $0.46^{* *}$ \\
Cynicism & $6.2 \pm 6.05^{* a}$ & $0.49^{* *}$ & $5.4 \pm 5.53$ & $0.51^{* *}$ \\
Extrinsic effort & $19.1 \pm 6.05^{* a}$ & $0.32^{* *}$ & $18.3 \pm 6.18$ & $0.32^{* *}$ \\
Reward & $28.1 \pm 7.51^{* * a}$ & $0.40^{* *}$ & $26.4 \pm 6.83$ & $0.35^{* *}$ \\
Effort/reward ratio & $1.28 \pm 0.38$ & 0.02 & $1.30 \pm 0.41$ & 0.08 \\
Professional efficacy & $23.5 \pm 9.48$ & $-0.22^{* *}$ & $24.5 \pm 9.44$ & $-0.33^{* *}$ \\
\hline
\end{tabular}

$*: p<0.05$. **: $p<0.01$ a: Comparison between men and women.

and meals in female doctors.

The contributions of risk factors to the model R-square are shown in Table 4. Among all clarified risk factors, the contribution to the model R-square attributed to work-related factors ( $\Delta \mathrm{R}$-square) was 0.2240 in male doctors and 0.2575 in female doctors. Health status contributed 0.1206 to the model R-square in male doctors and 0.1265 in female doctors. The model R-square value contributed by lifestyle factors ( $\Delta \mathrm{R}$-square) was 0.0345 for both male and female doctors.

\section{Discussion}

Anxiety is one of the most common conditions impairing quality of life. Our results revealed that the standard SAS scores were 46.8 in male doctors and 46.7 in female doctors respectively. In comparison with studies using the same anxiety indicator, our raw scores (37.8 in male doctors and 37.7 in female doctors) were close to the levels among survivors of severe acute respiratory syndrome, which were in the range of $37.2-43.0$ at $2,7,10,20$ and 46 months after discharge from medical hospitalization ${ }^{25)}$, but lower than that among airplane pilots $(44.56)^{26)}$; on the other hand, the standard scores were much higher than the anxiety status among university teachers (37.3 in male and 34.8 in female $)^{27)}$, and even a little higher than the level (45.36) among inhabitants in Wenchuan County after the 5.12 Sichuan earthquake ${ }^{28)}$. All these findings revealed that Chinese doctors were suffering from a considerably serious anxiety disorder at present. Unfortunately, comparison with the anxiety level before implementation of health care system reform could not be performed due to the lack of previous related assessments. But, according to our results, anxiety disorder among Chinese doctors requires urgent attention during the China-specific health care system reform for the quality of lives of the doctors and thereby the general population.

As for the risk factors, work-related psychological status was found to be crucial for anxiety disorder among Chinese doctors, coinciding with a previous conclusion $^{13)}$. Moreover, job burnout was found to have the strongest association with anxiety disorder among both male doctors and female doctors. It made up the major contribution to the model R-Square. Job burnout is an experience of physical, emotional and mental exhaustion caused by stress from work ${ }^{29)}$ and is characterized as emotional exhaustion, cynicism and reduced professional efficacy. The exhausted feeling produced by working seems to be a kind of personal erosion that makes an individual prone to anxiety disorder. Interestingly, among the three scales of job burnout, cynicism was revealed to have the strongest association with anxiety disorder in male doctors, whereas professional efficacy was the most crucial risk factor in female doctors. The reason for this sex-related difference is unclear. It might due to the higher education level of our female individuals than that of the male individuals. In China, women share the working burden and compete with men. For those women with a higher education, the accomplishment in work particularly represents the fulfillment of their lives and shows that they have value. This positive thinking certainly is able to help prevent anxiety disorder. As for men, they are accustomed to the task role assumed by traditional viewpoint. Comparably, interest in and passion for work seem to affect their attitude towards their career. Thus, attention regarding job burnout should be sex-specifically focused at improvement of anxiety disorder among Chinese doctors. In addition, job satisfaction was found to affect anxiety disorder among female doctors. This might result from women being more emotional than 
Table 2. The subject characteristics and the distributions of anxiety disorder in categorical items

\begin{tabular}{|c|c|c|c|c|c|}
\hline \multirow{2}{*}{ Variables } & & \multicolumn{2}{|c|}{ Male $(n=539)$} & \multicolumn{2}{|c|}{ Female $(n=595)$} \\
\hline & & $\mathrm{n}$ & Mean \pm SD & $\mathrm{n}$ & Mean \pm SD \\
\hline Marital status & $\begin{array}{l}\text { Others } \\
\text { Married }\end{array}$ & $\begin{array}{l}111 \\
415\end{array}$ & $\begin{array}{l}46.5 \pm 11.69 \\
46.7 \pm 11.00\end{array}$ & $\begin{array}{l}106 \\
470\end{array}$ & $\begin{array}{l}44.8 \pm 9.54 \\
47.0 \pm 11.05\end{array}$ \\
\hline Education & $\begin{array}{l}\text { Junior college } \\
\text { Undergraduate } \\
\text { Graduate }\end{array}$ & $\begin{array}{r}125 \\
374 \\
36\end{array}$ & $\begin{array}{l}44.0 \pm 10.75 \\
47.7 \pm 11.24 \\
45.9 \pm 9.58 * *\end{array}$ & $\begin{array}{c}97 \\
452 \\
43^{* a}\end{array}$ & $\begin{array}{l}46.3 \pm 11.12 \\
46.9 \pm 10.84 \\
45.3 \pm 10.31\end{array}$ \\
\hline Monthly income (dollars) & $\begin{array}{l}<292.8 \\
292.8-439.2 \\
>439.2\end{array}$ & $\begin{array}{r}361 \\
124 \\
53\end{array}$ & $\begin{array}{l}46.9 \pm 11.44 \\
47.1 \pm 10.71 \\
45.4 \pm 9.56\end{array}$ & $\begin{array}{r}404 \\
150 \\
40\end{array}$ & $\begin{array}{l}46.8 \pm 10.78 \\
47.1 \pm 11.01 \\
44.0 \pm 10.81\end{array}$ \\
\hline Chronic diseases & $\begin{array}{l}\text { Absent } \\
\text { Present }\end{array}$ & $\begin{array}{l}360 \\
179 * a\end{array}$ & $\begin{array}{l}45.2 \pm 10.95 \\
50.0 \pm 10.70^{* *}\end{array}$ & $\begin{array}{l}438 \\
157\end{array}$ & $\begin{array}{l}45.5 \pm 10.53 \\
50.1 \pm 11.04 * *\end{array}$ \\
\hline Sleeping problem & $\begin{array}{l}\text { No } \\
\text { Slight } \\
\text { Serious }\end{array}$ & $\begin{array}{r}196 \\
283 \\
47\end{array}$ & $\begin{array}{l}42.9 \pm 10.66 \\
48.2 \pm 10.71 \\
53.4 \pm 10.67 * *\end{array}$ & $\begin{array}{r}233 \\
276 \\
69\end{array}$ & $\begin{array}{l}42.6 \pm 10.03 \\
48.2 \pm 10.03 \\
54.3 \pm 10.96 * *\end{array}$ \\
\hline Smoking & $\begin{array}{l}\text { No } \\
\text { Yes }\end{array}$ & $\begin{array}{l}314 \\
220\end{array}$ & $\begin{array}{l}46.6 \pm 11.24 \\
47.0 \pm 10.94\end{array}$ & & \\
\hline Alcohol consumption & $\begin{array}{l}\text { No } \\
\text { Yes }\end{array}$ & $\begin{array}{l}191 \\
348^{* * a}\end{array}$ & $\begin{array}{l}46.0 \pm 11.90 \\
47.2 \pm 10.61\end{array}$ & $\begin{array}{r}542 \\
41\end{array}$ & $\begin{array}{l}46.4 \pm 10.76 \\
50.4 \pm 12.12 *\end{array}$ \\
\hline Meals & $\begin{array}{l}\text { Regular } \\
\text { Irregular }\end{array}$ & $\begin{array}{l}266 \\
273 * * a\end{array}$ & $\begin{array}{l}44.4 \pm 10.43 \\
49.1 \pm 11.24 * *\end{array}$ & $\begin{array}{l}416 \\
179\end{array}$ & $\begin{array}{l}45.0 \pm 10.41 \\
50.5 \pm 10.91 * *\end{array}$ \\
\hline Physical exercise & $\begin{array}{l}\text { None } \\
\text { Once a week } \\
\geq 2 \text { times/wk }\end{array}$ & $\begin{array}{l}212 \\
178 \\
121^{* * a}\end{array}$ & $\begin{array}{l}48.1 \pm 11.26 \\
46.9 \pm 10.81 \\
43.4 \pm 11.04 * *\end{array}$ & $\begin{array}{r}319 \\
178 \\
67\end{array}$ & $\begin{array}{l}47.2 \pm 10.92 \\
45.7 \pm 10.48 \\
45.0 \pm 11.40\end{array}$ \\
\hline Administrative leadership & $\begin{array}{l}\text { No } \\
\text { Yes }\end{array}$ & $\begin{array}{l}430 \\
109\end{array}$ & $\begin{array}{l}47.1 \pm 11.38 \\
45.3 \pm 9.80\end{array}$ & $\begin{array}{r}500 \\
95\end{array}$ & $\begin{array}{l}47.2 \pm 10.87 \\
44.0 \pm 10.36 * *\end{array}$ \\
\hline Professional rank & $\begin{array}{l}\text { Senior } \\
\text { Middle } \\
\text { Primary }\end{array}$ & $\begin{array}{l}157 \\
195 \\
174\end{array}$ & $\begin{array}{l}46.4 \pm 9.99 \\
47.1 \pm 11.14 \\
46.8 \pm 12.15\end{array}$ & $\begin{array}{l}191 \\
221 \\
178\end{array}$ & $\begin{array}{l}46.8 \pm 11.19 \\
47.7 \pm 10.79 \\
45.4 \pm 10.55\end{array}$ \\
\hline Work arrangement & $\begin{array}{l}\text { Fixed } \\
\text { Shift }\end{array}$ & $\begin{array}{l}209 \\
326\end{array}$ & $\begin{array}{l}45.4 \pm 10.77 \\
47.6 \pm 11.26^{*}\end{array}$ & $\begin{array}{l}244 \\
350\end{array}$ & $\begin{array}{l}45.8 \pm 10.96 \\
47.4 \pm 10.74\end{array}$ \\
\hline Night shift & $\begin{array}{l}\text { No } \\
\text { Yes }\end{array}$ & $\begin{array}{l}184 \\
355\end{array}$ & $\begin{array}{l}45.8 \pm 10.28 \\
47.3 \pm 11.47\end{array}$ & $\begin{array}{l}228 \\
367\end{array}$ & $\begin{array}{l}46.1 \pm 10.66 \\
47.0 \pm 10.96\end{array}$ \\
\hline Prepost training & $\begin{array}{l}\text { Yes } \\
\text { No }\end{array}$ & $\begin{array}{l}419 \\
103\end{array}$ & $\begin{array}{l}46.7 \pm 11.24 \\
47.4 \pm 10.63\end{array}$ & $\begin{array}{l}466 \\
104\end{array}$ & $\begin{array}{l}46.4 \pm 10.94 \\
47.9 \pm 10.48\end{array}$ \\
\hline On-the-job training & $\begin{array}{l}\text { Yes } \\
\text { No }\end{array}$ & $\begin{array}{r}493 \\
34\end{array}$ & $\begin{array}{l}46.7 \pm 11.10 \\
47.6 \pm 11.17\end{array}$ & $\begin{array}{r}537 \\
43\end{array}$ & $\begin{array}{l}46.6 \pm 10.74 \\
46.1 \pm 11.94\end{array}$ \\
\hline Bored with patients & $\begin{array}{l}\text { Never } \\
\text { General } \\
\text { Serious }\end{array}$ & $\begin{array}{r}74 \\
338 \\
122\end{array}$ & $\begin{array}{l}40.9 \pm 11.20 \\
46.1 \pm 10.42 \\
52.1 \pm 10.53^{* *}\end{array}$ & $\begin{array}{r}64 \\
403 \\
118\end{array}$ & $\begin{array}{l}43.4 \pm 10.58 \\
46.0 \pm 10.41 \\
50.5 \pm 11.45 * *\end{array}$ \\
\hline Effort/reward ratio & $\begin{array}{l}\leq 1 \\
>1\end{array}$ & $\begin{array}{l}107 \\
432\end{array}$ & $\begin{array}{l}45.6 \pm 11.37 \\
47.1 \pm 11.01\end{array}$ & $\begin{array}{l}126 \\
469\end{array}$ & $\begin{array}{l}44.2 \pm 10.20 \\
47.4 \pm 10.93^{* *}\end{array}$ \\
\hline
\end{tabular}

$*: p<0.05$. **: $p<0.01$ a: Comparison between men and women by chi-square test.

men.

With respect to health status, chronic diseases have been well documented as the basis for disorders ${ }^{12,}{ }^{19)}$, and having a sleeping problem was found to be a risk factor for psychological disorders such as depression, anxiety disorder and suicide ${ }^{30,31)}$. Among our participants, their impacts on anxiety disorder were also found in both male and female doctors. Interestingly, sleeping problem showed the second strongest association with anxiety disorder. Its contribution to the model R-Square accounted for $17.8 \%$ in male doctors and $23.6 \%$ in female doctors respectively, even if it was assessed by a single question. Having a sleeping problem will inevitably lead to tiredness and thereby 
Table 3. The general linear model analysis for clarifying the major risk factors for anxiety disorder

\begin{tabular}{|c|c|c|c|}
\hline Variables & Parameter estimate (B) & Standardized estimate $(\beta)$ & Model R-Square \\
\hline \multicolumn{4}{|l|}{ Male } \\
\hline Intercept & 40.46 & & \\
\hline Age (yr) & 0.03 & 0.03 & \\
\hline Cynicism & $0.51 * * *$ & 0.27 & \\
\hline Emotional exhaustion & $0.35 * * *$ & 0.25 & \\
\hline Professional efficacy & $-0.23 * * *$ & -0.19 & \\
\hline Sleeping problem (serious vs. no) & $4.36 * * *$ & 0.11 & \\
\hline Sleeping problem (slight vs. no) & $3.77 * * *$ & 0.17 & \\
\hline Chronic diseases (present vs. absent) & $2.31 * *$ & 0.10 & \\
\hline Physical exercise ( $\geq 2$ times/wk vs. no) & $-1.82 *$ & -0.07 & \\
\hline Physical exercise (once a week vs. no) & 0.39 & 0.02 & $0.3814 * * *$ \\
\hline \multicolumn{4}{|l|}{ Female } \\
\hline Intercept & 48.57 & & \\
\hline Age (yr) & 0.06 & 0.05 & \\
\hline Professional efficacy & $-0.29 * * *$ & -0.25 & \\
\hline Emotional exhaustion & $0.32 * * *$ & 0.22 & \\
\hline Cynicism & $0.37 * * *$ & 0.19 & \\
\hline Sleeping problem (serious vs. no) & $4.32 * * *$ & 0.13 & \\
\hline Sleeping problem (slight vs. no) & $2.97 * * *$ & 0.14 & \\
\hline Chronic diseases (present vs. absent) & $2.36 * * *$ & 0.10 & \\
\hline Job satisfaction & $-0.10 * * *$ & -0.10 & \\
\hline Alcohol consumption (yes vs. no) & $3.60 * *$ & 0.08 & \\
\hline Meals (irregular vs. regular) & $1.45^{*}$ & 0.06 & $0.4208 * * *$ \\
\hline
\end{tabular}

Table 4. The contributions of risk factors to the model R-square

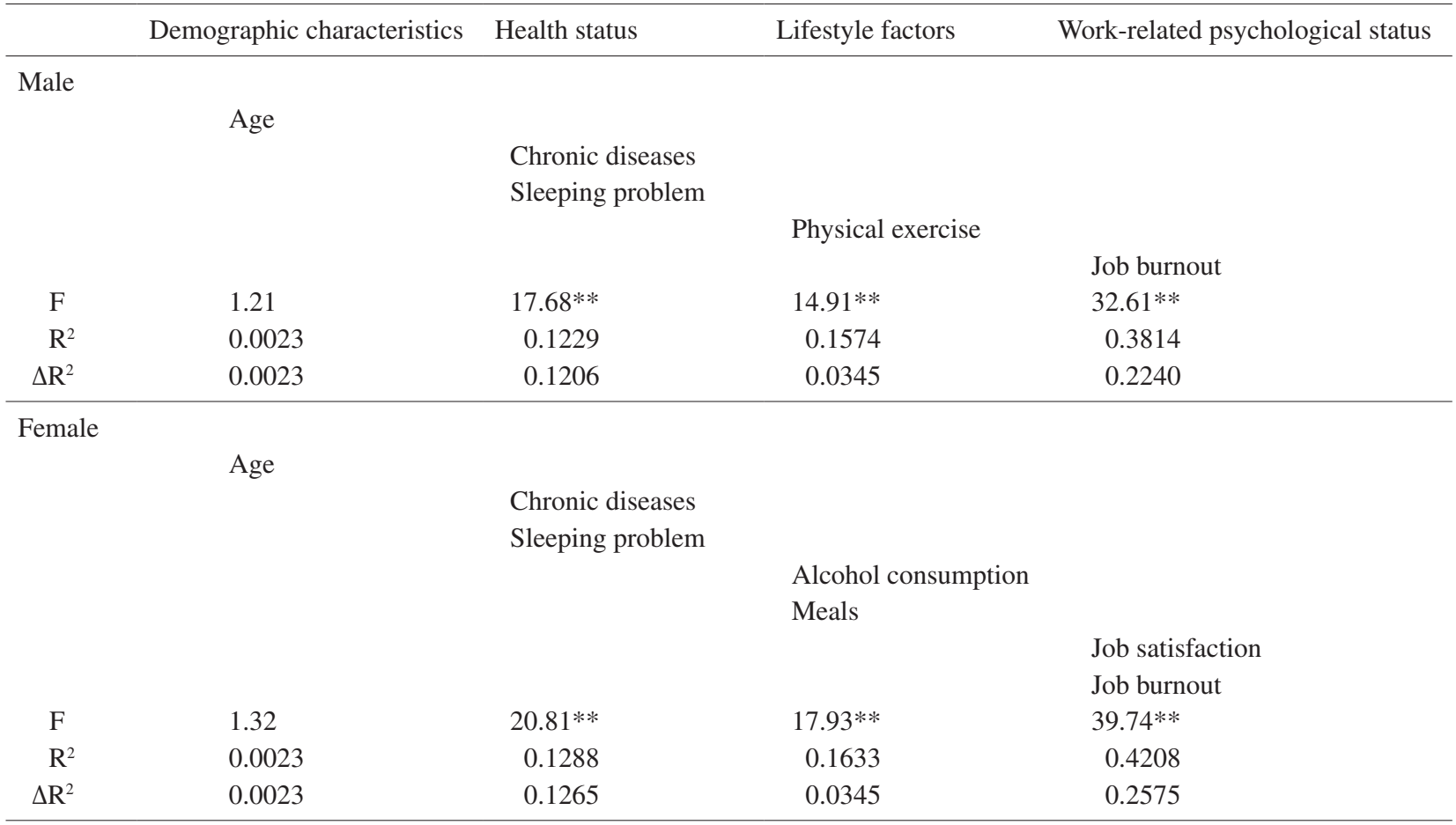

$* *: p<0.01$. 
weaken working ability and deteriorate work performance, which seems to be considerably harmful for doctors, a particular occupational population engaging in high stressful profession. This impairment seems to be especially serious in China due to the great number of patients yielded by the huge population. On the basis of this great patient load, having a sleeping problem tends to place an additional stressful burden on doctors and make them prone to anxiety disorder. Thus, the improvement of sleep quality seems to have an important role in lessening anxiety disorder for Chinese doctors.

Lifestyle factors have been revealed to be another main determinant of anxiety disorder ${ }^{15}$. Their effects on anxiety disorder were also observed in the present study. Among our assessed lifestyle factors, physical exercise, especially doing exercise twice or more a week, exerted an effect on anxiety disorder among male doctors, whereas alcohol consumption and irregular meals were risks for female doctors. Physical exercise has been considered important for restoration of personal resources ${ }^{32}$. The performance of physical exercise seems also to be a kind of personal stress relief. Thus, it plays an important role in preventing anxiety disorder. Unfortunately, only $11.9 \%$ of female doctors performed physical exercise twice or more a week in comparison to our male individuals $(23.7 \%)$. Consequently, its effect on anxiety disorder might be weakened among female doctors. In contrast, the prevalence of alcohol consumption in these female doctors was 7.0\%, 2.7 times the average level among female health workers in general hospitals ${ }^{33)}$, and $30.1 \%$ of them could not have regular meals. Even if these levels were much higher in male doctors, men usually have a much higher ability than women to adapt to or even to become accustomed to an irregular life style and thus cannot be affected easily.

There are two limitations to the present study. First, all individuals were drawn from the teaching hospitals of China Medical University. Although these hospitals are dispersed in all sizes of cities in Liaoning Province, which is located in northeastern China, the representation of our study population might be weakened. Second, our study was limited by its cross-sectional design. We were unable to draw any causal conclusion between anxiety disorder and its risk factors. All findings obtained in the present study need to be confirmed in future prospective studies.

In conclusion, the present study assessed anxiety disorder and explored its risk factors among Chinese doctors during China-specific reform of the health care system. Our findings revealed that both male and female doctors in China were at high risk of anxiety disorder. Work-related psychological status, especially job burnout, was a prominent risk factor for anxiety disorder for both male and female Chinese doctors. Health status such as having a sleeping problem seemed to have a considerable effect on anxiety disorder among Chinese doctors. Lifestyle factors were also able to affect anxiety disorder. Attention on preventing exhaustion from work and improving sleep quality should be focused on, especially during reform of the health care system, with the purpose of lessening anxiety disorder among doctors in China.

Competing Interests: The authors declare that they have no competing interests.

Acknowledgments: The authors would like to thank all the administrators in all teaching hospitals who helped to get the written informed consent about the conduct of this survey and to distribute the questionnaires to the subjects.

\section{References}

1) Pearson P. A brief history of anxiety (yours and mine). Toronto (ON): Random House Canada; 2007, p.13.

2) Tone A. Looking to the past: history, psychiatry, and anxiety. Can J Psychiatry 2005; 50: 373-80.

3) Kessler RC, Berglund P, Demler O, Jin R, Merikangas KR, Walters EE. Lifetime prevalence and age-of-onset distributions of DSM-IV disorders in the National Comorbidity Survey Replication. Arch Gen Psychiatry 2005; 62: 593-602.

4) Alonso J, Angermeyer MC, Bernert S, et al. Prevalence of mental disorders in Europe: results from the European Study of the Epidemiology of Mental Disorders (ESEMeD) project. Acta Psychiatr Scand 2004; Suppl. 420: 21-7.

5) Kessler RC, Chiu WT, Demler O, Merikangas KR, Walters EE. Prevalence, severity, and comorbidity of 12 month DSM-IV disorders in the National Comorbidity Survey Replication. Arch Gen Psychiatry 2005; 62: 617-27.

6) Merikangas KR, Zhang H, Avenevoli S, Acharyya $\mathrm{S}$, Neuenschwander M, Angst J. Longitudinal trajectories of depression and anxiety in a prospective community study: the Zurich cohort study. Arch Gen Psychiatry 2003; 60: 993-1000.

7) Stansfeld S, Candy B. Psychosocial work environment and mental health-a meta-analytic review. Scand J Work Environ Health 2006; 32: 443-62.

8) Tyssen R, Vaglum P. Mental health problems among young doctors: an updated review of prospective studies. Harv Rev Psychiatry 2002; 10: 154-65.

9) Landrigan CP, Rothschild JM, Cronin JW, et al. Effect of reducing interns' work hours on serious medical errors in intensive care units. $\mathrm{N}$ Engl J Med 2004; 351: 1838-48.

10) Lockley SW, Cronin JW, Evans EE, et al. Effect of reducing interns' weekly work hours on sleep 
and attentional failures. N Engl J Med 2004; 351: 1829-37.

11) Li J, Yang W, Cho SI. Gender differences in job strain, effort-reward imbalance, and health functioning among Chinese physicians. Soc Sci Med 2006; 62: 1066-77.

12) Wang JN, Sun W, Chi TS, Wu H, Wang L. Prevalence and associated factors of depressive symptoms among Chinese doctors: a cross-sectional survey. Int Arch Occup Environ Health 2010; 83: 905-11.

13) Dowbiggin IR. High anxieties: the social construction of anxiety disorders. Can J Psychiatry 2009; 54: 429-36.

14) Sateia MJ, Doghramji K, Hauri PJ, Morin CM. Evaluation of chronic insomnia. An American academy of sleep medicine review. Sleep 2000; 23: 243-308.

15) Averina M, Nilssen O, Brenn T, Brox J, Arkhipovsky VL, Kalinin AG. Social and lifestyle determinants of depression, anxiety, sleeping disorders and self-evaluated quality of life in Russia-a population-based study in Arkhangelsk. Soc Psychiatry Psychiatr Epidemiol 2005; 40: 511-8.

16) Olatunji BO, Deacon BJ, Abramowitz JS, Tolin DF. Dimensionality of somatic complaints: factor structure and psychometric properties of the Self-Rating Anxiety Scale. J Anxiety Disord 2006; 20: 543-61.

17) Zung WWk. A rating instrument for anxiety disorders. Psychosomatics 1971; 12: 371-9.

18) Wu H, Zhao Y, Wang JN, Wang L. Factors associated with occupational stress among Chinese doctors: a cross-sectional survey. Int Arch Occup Environ Health 2010; 83: 155-64.

19) Sun W, Watanabe M, Tanimoto Y, et al. Factors associated with good self-rated health of non-disabled elderly living alone in Japan: a cross-sectional study. BMC Public Health 2007; 7: 297.

20) Li J, Yang W, Cheng Y, Siegrist J, Cho SI. Effortreward imbalance at work and job dissatisfaction in Chinese healthcare workers: a validation study. Int Arch Occup Environ Health 2005; 78: 198-204.

21) Yang W, Li J. Measurement of psychosocial factors in work environment: application of two models of occupational stress. Chin J Ind Hyg Occup Dis
2004; 22: 422-6 (in Chinese).

22) Shao $\mathrm{H}$, Yan $\mathrm{S}, \mathrm{Hu} \mathrm{L}$. The work satisfaction degree of nurses in longgang district of Shenzhen city. J Nursing (China) 2007; 14: 12-4 (in Chinese).

23) Zhu W, Wang Z, Wang M, Lan Y, Wu S. Occupational stress and job burnout in doctors. J Sichuan Univ (Med Sci Edi) 2006; 37: 281-3 (in Chinese).

24) Zhu W, Wang Z, Wang M, Lan Y, Wu S. Job Burnout and Contributing Factors for Nurses. J Sichuan Univ (Med Sci Edi) 2006; 37: 632-5 (in Chinese).

25) Hong X, Currier GW, Zhao X, Jiang Y, Zhou W, Wei J. Posttraumatic stress disorder in convalescent severe acute respiratory syndrome patients: a 4-year followup study. Gen Hosp Psychiatry 2009; 31: 546-54.

26) Liang Z, Wang Y, Li J, Yu Y. Anxiety and influencing factors of civil air pilots. Int Medicine \& Health Guidance News 2005; 11: 20-2 (in Chinese).

27) Zhang D, Wang P, Gao F. Relationship between job satisfaction and anxiety: mediated by job burnout. Chin J Health Psychol 2011; 19: 943-5 (in Chinese).

28) Guo M, Gao Y, Wang X, Jiang X. Survey of anxiety and depression of people during Wenchuan earthquake. Chin Tropical Med 2009; 19: 383-4, 75 (in Chinese).

29) Maslach C, Goldberg J. Prevention of burnout: new perspectives. Applied Prevent Psychol 1998; 7: 63-74.

30) Taylor DJ, Lichstein KL, Durrence HH. Insomnia as a health risk factor. Behav Sleep Med 2003; 1: 227-47.

31) Taylor DJ, Lichstein KL, Durrence HH, Reidel BW, Bush AJ. Epidemiology of insomnia, depression, and anxiety. Sleep 2005; 28: 1457-64.

32) Osipow SH. Occupational stress inventory revised edition. Odessa (FL): Psychological Assessment Resources Inc; 1998. p.1-10.

33) Zu Q, Zhu Q, Zhu X, Shen H, You H, Yu R. Investigation of the relationship between smoking, drinking and mental health status of medical staff in comprehensive hospitals. Acta Universitatis Medicinalis Nanjing (Natural Science) 2008; 28: 1214-7 (in Chinese). 